OPEN ACCESS

Edited by:

Hani Harb,

Boston Children's Hospital, Harvard Medical School, United States

Reviewed by:

Susetta Finotto,

University Hospital Erlangen, Germany Sin-Hyeog Im

Pohang University of Science and Technology, South Korea

*Correspondence:

Diego G. Peron

diego.peroni@unipi.it

Specialty section:

This article was submitted to Immunological Tolerance and

Regulation,

a section of the journal

Frontiers in Immunology

Received: 10 April 2020

Accepted: 08 June 2020

Published: 14 July 2020

Citation:

Di Gangi A, Di Cicco ME, Comberiati P and Peroni DG (2020) Go With Your Gut: The Shaping of T-Cell Response by Gut Microbiota in Allergic Asthma.

Front. Immunol. 11:1485. doi: 10.3389/fimmu.2020.01485

\section{Go With Your Gut: The Shaping of T-Cell Response by Gut Microbiota in Allergic Asthma}

\author{
Alessandro Di Gangi ${ }^{1}$, Maria Elisa Di Cicco ${ }^{1}$, Pasquale Comberiati ${ }^{1,2}$ and Diego G. Peroni ${ }^{1 *}$ \\ ${ }^{1}$ Department of Clinical and Experimental Medicine, Section of Pediatrics, University of Pisa, Pisa, Italy, ${ }^{2}$ Department of \\ Clinical Immunology and Allergology, I.M. Sechenov First Moscow State Medical University, Moscow, Russia
}

Novel methods in immunological research and microbiome evaluation have dramatically changed several paradigms associated with the pathogenesis of allergic asthma (AAS). Ovalbumin and house dust mite-induced AAS in germ-free or specific pathogen-free mice are the two leading experimental platforms that significantly contribute to elucidate the relationship between AAS and gut microbiota. Beyond the exacerbation of $\mathrm{T}$ helper (Th) 2 responses, a complex network of immunological interaction driven by gut microbiota could modulate the final effector phase. Regulatory $T$ cells are abundant in gastrointestinal mucosa and have been shown to be pivotal in AAS. The gut microbiota could also influence the activity of other T cell subsets such as Th9, Th17, and populations of effector/memory T lymphocytes. Furthermore, gut microbiota metabolites drive the hematopoietic pattern of dendritic cells and ameliorate lung Th2 immunity in AAS models. The administration of probiotics has shown conflicting results in AAS, and limited evidence is available on the immunological pathways beyond their activity. Moreover, the impact of early-life gut dysbiosis on AAS is well-known both experimentally and clinically, but discrepancies are observed between preclinical and clinical settings. Herein, our aim is to elucidate the most relevant preclinical and clinical scenarios to enlighten the potential role of the gut microbiota in modulating $T$ lymphocytes activity in AAS.

\section{Keywords: gut microbiota, asthma, children, $\mathrm{T}$ lymphocytes, microbiome}

\section{T CELL PLASTICITY AND GUT MICROBIOTA}

During homeostatic periods, gut-microbiota and T-cells within the gut mucosa engaged profitable crosstalk capable of shaping the systemic immune response of the individual. T-cell-receptors are reactive to microbiota-derived antigens that are necessary for an adequate maturation of the immune system and to ensure proper colonization of the gut lumen. Heterogeneous microbiota-derived signals could drive the polarization of Th cells into four different categories: while Th1 (1) and Th17 (2) dysregulation are relevant in inflammatory and autoimmune diseases, GATA3 $^{+}$Th2 responses (3) and T regulatory lymphocytes (Tregs) (4) are pivotal in allergic responses. Some bacteria metabolites, such as short-chain fatty acids (SCFAs), could regulate the tolerogenic effect of Tregs and they are directly sensed by G-protein-coupled-receptors (GPCRs) (5). Alternatively, Tregs polarization could be promoted by an IL-10 dependent pathway from microbiota-derived antigen presentation by dendritic cells (DCs) (6). Several other Th subsets such as Th9 (7) and Tregs subtypes (8) are implicated in allergic responses while their relationship with the gut microbiota is not entirely defined. Furthermore, the role of Th17 in AAS was heavily investigated (9) and they are currently recognized as one of the crucial mediators of AAS. 


\section{WHAT WE HAVE LEARNED FROM GUT MICROBIOTA MANIPULATION IN MURINE MODELS OF ALLERGIC ASTHMA}

More than a decade ago, evidence in murine models rose in support of the hygiene hypothesis, when Th2 response was associated with a state of gut dysbiosis (10). Nowadays, the paradigm has evolved, and the complex immunological network beyond the gut-lung axis is under active research.

\section{The Role of Clostridium spp Emphasize Regulatory T-Cell Activity}

A number of studies identified Clostridium $s p p$ as crucial modulators of AAS. First, insights come from the investigation on the impact of antibiotic therapies on $\mathrm{T}$ cell populations. It was demonstrated that $\mathrm{CD} 4{ }^{+} \mathrm{CD} 25^{+} \mathrm{FoxP}^{+}$Tregs are slightly reduced when mice are treated with polymixin $\mathrm{B}$ or vancomycin but not streptomycin withing the intestinal wall, while lung Tregs frequencies are comparable among vancomycin or streptomycin-treated animals or controls $(11,12)$. Interestingly, the ovalbumin (OVA) challenge exacerbates AAS in vancomycin-treated animals but not within the streptomycin group (12). It is well-known that vancomycin preferentially targets Clostridium spp. In order to further elucidate the role of these strains in AAS, stool transfer experiments between mice were conducted. Murine models colonized with fecal water derived from mice supplemented with a mixture of Clostridium strains have demonstrated a higher percentage of IL $10^{+}$CTLA$4^{\text {high }}$ IKZF2 $^{-}$colonic Tregs when compared to controls while a similar approach with Lactobacillus spp and Bacteroides spp failed to show any significant variation (11). Of note, in this context, Tregs does not express IKZF2, an essential transcription factor that is necessary for the stabilization of their suppressive activity in autoinflammatory models (13). A similar approach with fecal material from human volunteers has demonstrated that clusters of Clostridia IV/XIV and XVIII are able to increase the frequency of $\mathrm{IL}_{10}{ }^{+} \mathrm{ICOS}^{+} \mathrm{CTLA}^{+} \mathrm{CD} 25^{+}$Tregs in colon mucosa and they are implicated in protection against OVA-induced Th2 colitis (14). However, their relevance in AAS is under debate. One of the significant limitations of these studies is represented by the absence of a detailed functional characterization of Tcells; for instance, IL-10 and CTLA- 4 are essential for the immunosuppressive activity of Tregs, while ICOS is crucial for their effector activity rather than their induction (15) thus, the contribution of different $\mathrm{T}$ effector/memory (Tem) populations should be addressed.

\section{The Importance of Effector/Memory T Cells Revealed by Bacteroides spp}

Observations in AAS models enhance the role of Bacteroides $s p p$. Even if they are not a direct target of vancomycin, perinatal treatment in mice reduces Bacteroides spp and relatively increases Lactobacillus spp (16). Importantly, the effect of vancomycin on AAS is evident only during early-life and not during adulthood, identifying a specific "window of opportunity" (16). Mechanistic studies on Bacteroides fragilis in AAS provide further insights into the regulation of $\mathrm{T}$ cell response. In other settings, it was shown that the polysaccharide A (PSA) is a non-protein antigen presented by MHC-II (17) capable of activating CD4 ${ }^{+}$ cells (18). The oral exposure to PSA protects murine models against AAS trough a T-cell mediated pathway (19). PSA usually elicits a FoxP3 ${ }^{+}$peripheral Tregs response in mice and FoxP3 ${ }^{-}$ Tregs cells in humans (20). However, in mice primed with PSA and sensitized to OVA, the PSA-responding population is not composed of $\mathrm{FoxP}^{+}$Tregs but relies on IL-10 to exert its protective effect (19). Thus, it seems that PSA could protect against AAS through an IL-10 dependent mechanism, but the source of IL-10 was unclear. The adoptive transfer approach of PSA-responding $\mathrm{CD}_{4}^{+} \mathrm{T}$ lymphocytes between $\mathrm{IL} 10^{-/-}$and wild type animals allows the recognition that PSA-responding $\mathrm{T}$ cells are a population of FoxP $3{ }^{-} \mathrm{CD} 45 \mathrm{Rb}^{\text {low }} \mathrm{CD} 44^{+} \mathrm{CD} 62 \mathrm{~L}^{-} \mathrm{Tem}$ that support the production of IL-10 by lung resident FoxP3 ${ }^{+}$ Tregs (21). To date, it is not known if other gut-derived antigens could act indirectly on lungs $\mathrm{T}$ response in a similar way.

\section{Modulation of the Gut-Lung Axis Through Antibiotics and Probiotics Impacts the T-Cell Response}

Mice treated with a combined intermittent antibiotic regimen early after weaning and subsequently challenged with house dust mite (HDM) show a significant reduction of the $\mathrm{FoxP}^{+} / \mathrm{CD}^{+}$ ratio in mediastinal lymph nodes (MLNs), that is proportional to the Simpson diversity index variation of the fecal microbiome (22). Therefore, a direct link between Tregs homeostasis and gut microbiota in AAS exists, and a state of dysbiosis could strongly influence the severity of Th2-mediated inflammation. Among the limitations of this approach, the use of aggressive and intensive antibiotic regimens is one of the most relevant obstacles for translation into clinical practice. Although direct evidence of its implication in AAS is currently lacking, other works address the long-lasting immunomodulatory effects of an early-life single macrolide course vs. a three pulses course (23). In this context, intestinal $\mathrm{CD} 4^{+} \mathrm{IL}_{17 \mathrm{~A}^{+}} \mathrm{T}$ lymphocytes are decreased while $\mathrm{CD} 4^{+} \mathrm{IFN}-\gamma \mathrm{T}$ cells are not affected, and $\mathrm{CD}^{+} \mathrm{FoxP}^{+}$Tregs percentage is only slightly increased among treated animals (23). Of note, only slight differences are noted in germ-free mice, and the degree of systemic immune perturbance of a single macrolide pulse is relatively modest, but it is strong enough to induce an imbalance in local Th17 immunity, leading to long-lasting microbiome alterations (23). It would be of great interest to explore Tcell development in a similar model challenged with HDM or OVA.

Since transient gut dysbiosis is relatively common in children due to the widespread use of antibiotics (24), it is possible that an early probiotic administration could recover this state and drive the Th1/Th2 balance. Supplementation with Lactobacillus Ramnosus or Bifidobacterium lactis is proven to be an efficient AAS suppressor and a robust inductor of FoxP3 $^{+}$Tregs in MLNs of newborn OVA-sensitized mice (25). Moreover, the proliferative response to probiotic administration enhances the production of TGF- $\beta$ secreting $\mathrm{CD} 4^{+} / \mathrm{CD}^{+} \mathrm{T}$ 
lymphocytes (25), thereby contributing to the establishment of a tolerogenic environment. Probiotic treatment has been shown to be effective in protecting newborn mice against AAS while it has been proven to be ineffective in adult mice. Interestingly, both adult and newborn mice are able to induce a $\mathrm{CD}^{+} \mathrm{FoxP}^{+}$Treg response in the lungs after probiotic administration, but when splenocytes from tolerant wild-type mice were adoptively transferred into adult mice, only newborn's Tregs are able to control pulmonary inflammation (26). Therefore, the generation of Tregs itself is not sufficient to confer protection to AAS, but an intrinsic feature of neonatal Tregs is necessary (26), and it would be of great interest for future research.

\section{Diet Modulation of T Cell Response Is Only Partially Driven by Gut Microbiota Alterations}

Environmental factors play a crucial role in the development of AAS, and specific maternal diets could be beneficial in preventing the onset of AAS. Bacteria metabolize fermentable dietary fiber into SCFAs, small soluble molecules that could trigger strong immunomodulatory effects (27). SCFAs diet content is capable of driving the gut microbiota composition, and this shift could lead to significant protection against AAS (5). Interestingly, vancomycin treatment in mice mainly delates bacteria capable of producing SCFAs (28).

After a high-fiber diet, the gut microbiota is enriched with Bacteoidaceae and Bifidobacteriaceae, while SCFAs, particularly acetate and propionate, increased (5). However, SCFAs are not detected in lung tissue after HDM challenges; thus, they exert their action through an indirect mechanism (5). Furthermore, butyrate enhances the extrathymic generation of Tregs (29), but a high-fiber diet was not associated with an increase in $\mathrm{CD}_{2} 5^{+}$FoxP $^{+}$Tregs (5). Therefore, other mechanisms should underline this effect. Bone-marrow derived DCs were investigated as possible metabolite-specific mediators. It was demonstrated that butyrate significantly alters DCs gene expression, reduces costimulatory molecules and impairs CCL19-dependent DCs migration (28). On the other hand, propionate acts via GPCRs in a context-dependent manner, enhancing the hematopoietic activity of DCs precursors that could impair Th2 activity in the lungs (Figure 1) (27). Therefore, gut microbiota diet perturbations could indirectly affect the Th2 response through the modulation of the hematopoietic activity in the bone marrow through a metabolite-specific pathway. In addition to this mechanism, SCFAs can establish an anti-inflammatory activity by the direct interaction with the histone deacetylase (HDAC) protein family (30). Of note, HDAC proteins confer a permissive chromatin structure that enhances the transcription of involved regions (27). Propionate, but not acetate, could inhibit HDACs, enhancing the extrathymic Treg generation promoted by butyrate (29). According to this finding, dramatic protection against AAS after HDM exposure in progeny was related to the downregulation of Nppa that inhibits HDAC-9 and increases the acetylation rates of the FoxP3 promoter (30). Furthermore, this action was reported as independent from the microbiota shift observed in treated mice (30).

Other T-cell subsets could be involved in SCFAs-mediated protection against AAS. In newborn mice treated with a commercially available mixture of probiotics, increased levels in butyrate, but not other metabolites, are able to induce the proliferation of Tregs and negatively modulate OVA-induced AAS (31). Since Tregs are potent inhibitors of Th9 (32), their capacity to reduce IL-9 expression and Th9 differentiation was assessed. Butyrate-treated mice show lower frequencies of Th9 cells in the lungs, while no difference is observed for Th2 cells (31). Moreover, adoptive transfer of Th9 or IL-9 administration could revert the protective effect of butyrate, indicating that the mechanisms are partially related to this Th subclass (31). Lastly, while the link between obesity and non-allergic bronchial hyperresponsiveness is widely accepted, a high-fat diet has little effect in modulating Tregs responses by an impairment of DCs activation in OVA-induced AAS (33). Therefore, diet could have a significant role during early developmental stages, and it is capable of shaping the T-cell effector phase through a variety of mechanisms.

\section{The Hidden World: Fungi and Viruses}

Fungal dysbiosis was recently recognized as one of the foremost promoters of AAS in experimental models, but the mechanisms are only partially understood. Fluconazole can exacerbate AAS in mice and increase $\mathrm{IL}-4^{+} \mathrm{CD} 4^{+}$and $\mathrm{IL}-13^{+} \mathrm{CD} 4^{+}$T-cells (34). In another study, Wallemia mellicola colonizes the intestine efficiently after depletion of resident microbiota by wide-spectrum antibiotics and promotes the accumulation of IL- $13^{+} \mathrm{CD} 4{ }^{+}$T-cells in MLNs and AAS exacerbations (35). Therefore, the induction of Th2 responses seems to be cardinal during mycobiota dysbiosis. However, C. albicans spp. were able to increase AAS susceptibility through $\operatorname{ROR} \delta \mathrm{T}^{+}$T-cells (36) and recent findings in mice treated with fluconazole and then "recovered" with oral gavage of three dysbiotic fungal species demonstrate that AAS susceptibility is mediated by a mixed GATA $^{+}$and $\operatorname{ROR} \delta \mathrm{T}^{+}$T-cell response (37). Therefore, both Th2 and Th17 are involved in AAS during mycobiota dysbiosis, but further studies are needed to enlighten the mechanisms and possible therapeutic opportunities. Of note, Th17 are induced under the presence of both IL- 6 and TGF- $\beta$ while the absence of IL- 6 promotes the differentiation into Tregs (4). To our knowledge, there is a lack of evidence on mechanisms that could link intestinal viruses and T lymphocytes response in AAS; it would be of great interest to address this topic in the near future.

\section{WHAT HAVE WE LEARNED FROM BIRTH COHORTS AND OTHER EPIDEMIOLOGICAL OR CLINICAL EVIDENCE?}

Alterations within the gut microenvironment are linked to AAS in children (38). Several studies suggest a negative correlation between farming lifestyle during early life and the risk of AAS $(39,40)$ while others identify a specific role for farm-milk 


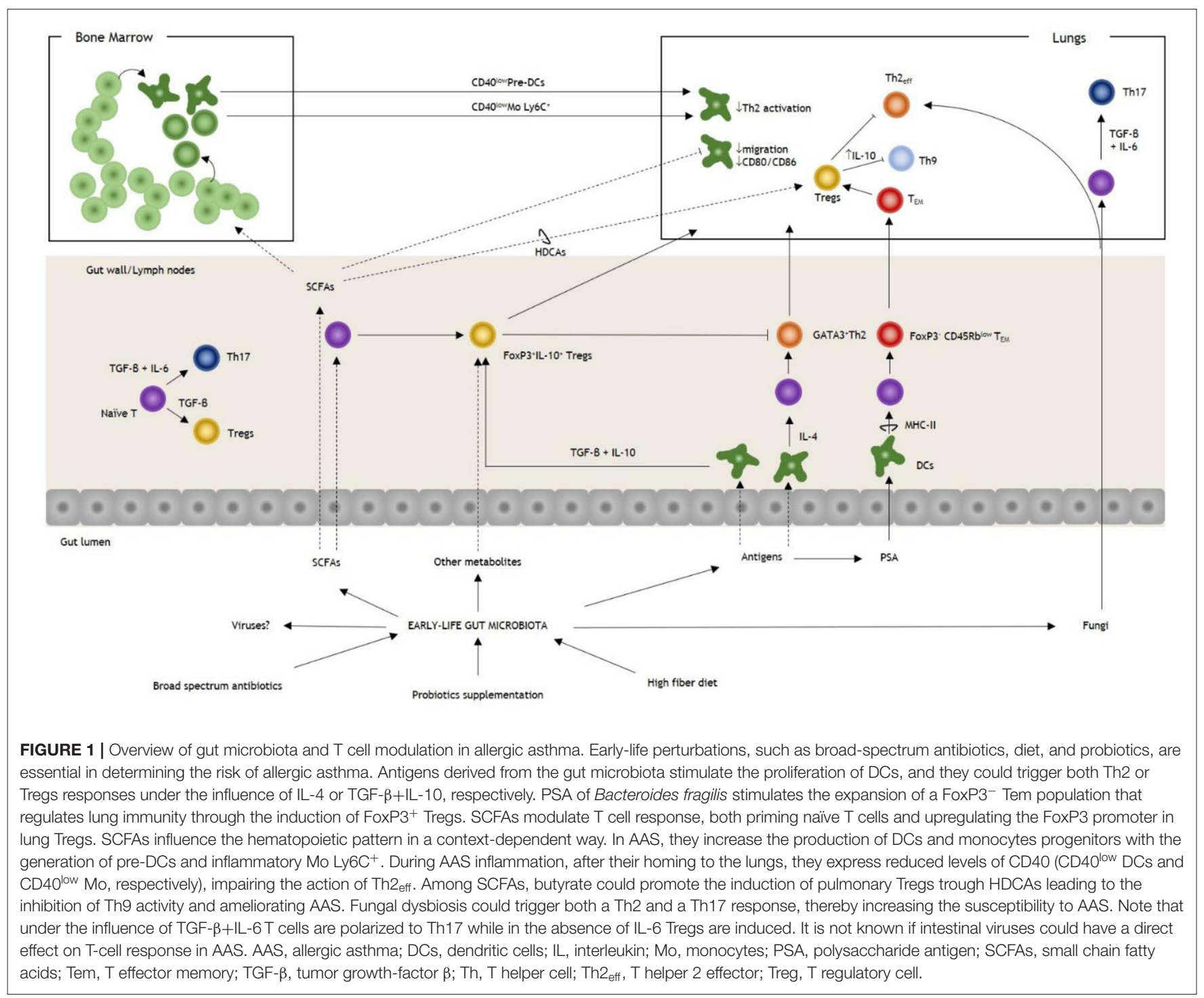

consumption (41). Since "correlation does not imply causation," evidence on the underlying immune mechanisms is needed.

\section{T Regulatory Populations: Tricks or Treat?}

Recent findings show that the neonatal gut microbiota is different among children concerning AAS risk, and prove a different propensity to induce specific $T$ cell responses. The analysis of gut microbiota of the WHEAL cohort, in which neonates and infants are clustered for AAS risk, demonstrates that neonates at higher risk exhibit a delayed diversification of the gut microbiota and a relative difference in the composition with fewer Lactobacillus, Bifidobacterium, Akkermisia and Faecalicaterium and more Candida spp (42). Sterile fecal water from these subjects impairs in vitro Tregs differentiation, while a reduction of $\mathrm{CD} 4{ }^{+} \mathrm{CD} 25^{+} \mathrm{FoxP}^{+}{ }^{+}$Tregs and an increase in IL- $4^{+} \mathrm{CD} 4^{+} \mathrm{T}$ cells is observed (42).

The analysis of peripheral blood cells in PASTURE and EFRAIM children cohorts display an increase in
$\mathrm{CD} 4{ }^{+} \mathrm{CD} 25^{+} \mathrm{FoxP}^{+}$Tregs at 4.5 years (43) and a subsequent reduction at 6 years of age (44). Farm-milk is associated with a protective effect on AAS at 4.5 years of age, and this protection is partially dependent on Tregs. Beyond the number, the demethylation pattern of the FoxP3 promoter increases in farm-milk children but not in children with farm-exposure only (43). However, the longitudinal assessment of this cohort at 6 years of age finds no differences in functional assays nor Tregs frequencies among high or low farm milk intake groups, but an increased expansion of Tregs after LPS stimulation was demonstrated in children affected by AAS (44). Together, these studies support the hypothesis that the number of Tregs in peripheral blood is not a hallmark of tolerogenic responses.

\section{The Impact of Antibiotics: A Difficult Assessment in "Real-Life"}

Some studies address the role of early antimicrobials administration and AAS. Early exposure to beta-lactams or 
macrolides has a differential impact on the development of the microbial community in children (45). Infants who are exposed to antibiotics early in life are more prone to develop AAS in a variety of cohort studies, but it is difficult to extract some conclusions on the shaping action on T cell response. Since oral intake is one of the most common routes of administration, it is rational to hypothesize a connection between antibiotics induced gut-dysbiosis and a Th2 polarized response. However, to our knowledge, no clustered analysis is available to date and evidence that link antibiotics induced gut dysbiosis and $\mathrm{T}$ cell response in AAS are currently lacking in these clinical scenarios.

\section{Effects of Preventive Probiotics Administration on T-Cell in Children}

Interestingly, Lactobacillus spp is a constituent of genitourinary microflora and is an essential element of the microbiota in vaginally delivered-infants (46). Several shreds of evidence remark the role of delivery mode in determining the AAS risk in children, but other studies find no differences between elective cesarean and vaginal delivery (47). Lactobacillus is one of the strains depleted in high-risk toddlers; thus, it is hypothesized that supplementation could prevent the onset of AAS in children through a persistent modification of the microbiota. Since the therapeutic window is probably confined within the first year of life, the longitudinal comparison of stool samples collected from infants at high risk of AAS, treated, respectively, with Lactobacillus rhamnosus $G G$ or placebo for 6 months was performed (48). While children at high risk show a distinct meconium microbiota and an impaired gut diversification, the treatment with Lactobacillus rhamnosus is able to restore this alteration at 6 months of life, but this effect is lost at 1 year of age (48). Moreover, sterile fecal water from infants at high risk treated with Lactobacillus rhamnosus at 6 months, but not at 12 months, promotes $\mathrm{CD}^{+}{ }^{+} \mathrm{CD} 25^{+} \mathrm{FoxP}^{+} \mathrm{T}$ regs expansion and IL-10

\section{REFERENCES}

1. Romagnani S. Human TH1 and TH2 subsets: Regulation of differentiation and role in protection and immunopathology. Int Arch Allergy Immunol. (1992) 98:279-85. doi: 10.1159/000236199

2. Ivanov II, McKenzie BS, Zhou L, Tadokoro CE, Lepelley A, Lafaille JJ, et al. The orphan nuclear receptor $\operatorname{ROR} \gamma \mathrm{t}$ directs the differentiation program of proinflammatory IL-17+ T helper cells. Cell. (2006) 126:1121-33. doi: 10.1016/j.cell.2006.07.035

3. Das J, Chen CH, Yang L, Cohn L, Ray P, Ray A. A critical role for NF-кB in Gata3 expression and TH2 differentiation in allergic airway inflammation. Nat Immunol. (2001) 2:45-50. doi: 10.1038/83158

4. Doganci A, Eigenbrod T, Krug N, De Sanctis GT, Hausding M, Erpenbeck VJ, et al. The IL-6R $\alpha$ chain controls lung CD4+CD25+ Treg development and function during allergic airway inflammation in vivo. J Clin Invest. (2005) 115:313-25. doi: 10.1172/JCI200522433

5. Trompette A, Gollwitzer ES, Yadava K, Sichelstiel AK, Sprenger N, Ngom-Bru $\mathrm{C}$, et al. Gut microbiota metabolism of dietary fiber influences allergic airway disease and hematopoiesis. Nat Med. (2014) 20:159-66. doi: 10.1038/nm.3444

6. Josefowicz SZ, Niec RE, Kim HY, Treuting P, Chinen T, Zheng Y, et al. Extrathymically generated regulatory $\mathrm{T}$ cells control mucosal TH2 inflammation. Nature. (2012) 482:395-9. doi: 10.1038/nature 10772 production in DC/T-cell assays (48). Therefore, Lactobacillus rhamnosus $G G$ could promote a tolerogenic environment, but it does not persist. Of note, a randomized, double-blind controlled trial of Lactobacillus rhamnosus supplementation during the first six months of life failed to show any significant difference in AAS at 5 years of age (49). Significant limitations of these studies include the intrinsic difficulty in controlling confounding factors and the heterogeneous definitions of atopy risk and AAS. A deeper immunological characterization in infants treated with probiotics in relation to the risk of AAS is needed.

\section{CONCLUSIONS}

The complex interactions between the gut microbiota and the T-cell response in AAS are only partially uncovered. Further pathways should be outlined such as the relationship with lungs resident memory $\mathrm{T}$ cells (50), the induction of differential response in effector or central memory Th2 (51) or if an immune shift similar to those observed during immunotherapy (52) could be achieved by microbiome manipulation. Clinical trials are difficult and sometimes tainted by several confounding factors and rarely emphasize aspects related to the $\mathrm{T}$ cell responses. Moreover, when perinatal interventions are considered, the result should be clustered into pre, post, and combinatory ones in order to understand the priming effect of the delivery mode (49). The clarification of the mechanisms beyond the gut-lung axis strongly encourages further efforts to explore the potential therapeutic roles of microbiota-based primary prevention of AAS during early infancy.

\section{AUTHOR CONTRIBUTIONS}

All authors listed have made a substantial, direct and intellectual contribution to the work, and approved it for publication.

7. Badolati I, Sverremark-Ekström E, van der Heiden M. Th9 cells in allergic diseases: a role for the microbiota? Scand J Immunol. (2019) 91:e12857. doi: $10.1111 /$ sji. 12857

8. Zhang H, Kong H, Zeng X, Guo L, Sun X, He S. Subsets of regulatory $\mathrm{T}$ cells and their roles in allergy. J Transl Med. (2014) 12:125. doi: 10.1186/1479-5876-12-125

9. Choy DF, Hart KM, Borthwick LA, Shikotra A, Nagarkar DR, Siddiqui S, et al. TH2 and TH17 inflammatory pathways are reciprocally regulated in asthma. Sci Transl Med. (2015) 7:301ra129. doi: 10.1126/scitranslmed. aab3142

10. Noverr MC, Noggle RM, Toews GB, Huffnagle GB. Role of antibiotics and fungal microbiota in driving pulmonary allergic responses. Infect Immun. (2004) 72:4996-5003 doi: 10.1128/IAI.72.9.4996-5003.2004

11. Atarashi K, Tanoue T, Shima T, Imaoka A, Kuwahara T, Momose Y, et al. Induction of colonic regulatory $\mathrm{T}$ cells by indigenous Clostridium species. Science. (2011) 331:337-4. doi: 10.1126/science.1198469

12. Russell SL, Gold MJ, Hartmann M, Willing BP, Thorson L, Wlodarska M, et al. Early life antibiotic-driven changes in microbiota enhance susceptibility to allergic asthma. EMBO Rep. (2012) 13:440-7. doi: 10.1038/embor. 2012.32

13. Kim HJ, Barnitz RA, Kreslavsky T, Brown FD, Moffett H, Lemieux ME, et al. Stable inhibitory activity of regulatory $\mathrm{T}$ cells requires the transcription factor Helios. Science. (2015) 350:334-9. doi: 10.1126/science.aad0616 
14. Atarashi K, Tanoue T, Oshima K, Suda W, Nagano Y, Nishikawa H, et al. Treg induction by a rationally selected mixture of Clostridia strains from the human microbiota. Nature. (2013) 500:232-6. doi: 10.1038/nature 12331

15. Weiner HL, da Cunha AP, Quintana F, Wu H. Oral tolerance. Immunol Rev. (2011) 241:241-59. doi: 10.1111/j.1600-065X.2011.01017.x

16. Russell SL, Gold MJ, Willing BP, Thorson L, McNagny KM, Finlay BB. Perinatal antibiotic treatment affects murine microbiota, immune responses and allergic asthma. Gut Microbes. (2013) 4:158-64. doi: 10.4161/gmic. 23567

17. Cobb BA, Wang Q, Tzianabos AO, Kasper DL. Polysaccharide processing and presentation by the MHCII pathway. Cell. (2004) 117:677-87. doi: 10.1016/j.cell.2004.05.001

18. Chung DR, Kasper DL, Panzo RJ, Chtinis T, Grusby MJ, Sayegh MH, et al. CD4 $+\mathrm{T}$ cells mediate abscess formation in intra-abdominal sepsis by an IL-17-dependent mechanism. J Immunol. (2003) 170:1958-63. doi: 10.4049/jimmunol.170.4.1958

19. Johnson JL, Jones MB, Cobb BA. Bacterial capsular polysaccharide prevents the onset of asthma through T-cell activation. Glycobiology. (2015) 25:368-75. doi: $10.1093 /$ glycob/cwu117

20. Kreisman LSC, Cobb BA. Glycoantigens induce human peripheral Tr1 cell differentiation with gut-homing specialization. J Biol Chem. (2011) 286:88108. doi: 10.1074/jbc.M110.206011

21. Johnson JL, Jones MB, Cobb BA. Polysaccharide-experienced effector $T$ cells induce IL-10 in FoxP3+ regulatory $\mathrm{T}$ cells to prevent pulmonary inflammation. Glycobiology. (2018) 28:50-8. doi: 10.1093/glycob/ cwx093

22. Adami AJ, Bracken SJ, Guernsey LA, Rafti E, Maas KR, Graf J, et al. Earlylife antibiotics attenuate regulatory $\mathrm{T}$ cell generation and increase the severity of murine house dust mite-induced asthma. Pediatr Res. (2018) 84:426-34. doi: 10.1038/s41390-018-0031-y

23. Ruiz VE, Battaglia T, Kurtz ZD, Bijnens L, Ou A, Engstrand I, et al. A single early-in-life macrolide course has lasting effects on murine microbial network topology and immunity. Nat Commun. (2017) 8:518. doi: 10.1038/s41467-017-00531-6

24. Vangay P, Ward T, Gerber JS, Knights D. Antibiotics, pediatric dysbiosis, and disease. Cell Host Microbe. (2015) 17:553-64. doi: 10.1016/j.chom.2015. 04.006

25. Feleszko W, Jaworska J, Rha RD, Steinhausen S, Avagyan A, Jaudszus A, et al. Probiotic-induced suppression of allergic sensitization and airway inflammation is associated with an increase of $\mathrm{T}$ regulatory-dependent mechanisms in a murine model of asthma. Clin Exp Allergy. (2007) 37:498505. doi: 10.1111/j.1365-2222.2006.02629.x

26. Nunes CF, Nogueira JS, Vianna PHO, Ciambarella BT, Rodrigues PM, Miranda KR, et al. Probiotic treatment during neonatal age provides optimal protection against experimental asthma through the modulation of microbiota and T cells. Int Immunol. (2018) 30:155-69. doi: 10.1093/intimm/dxy011

27. Dang AT, Marsland BJ. Microbes, metabolites, and the gut-lung axis. Mucosal Immunol. (2019) 12:843-50. doi: 10.1038/s41385-019-0160-6

28. Cait A, Hughes MR, Antignano F, Cait J, Dimitriu PA, Maas KR, et al. Microbiome-driven allergic lung inflammation is ameliorated by short-chain fatty acids. Mucosal Immunol. (2018) 11:785-95. doi: 10.1038/mi.2017.75

29. Arpaia N, Campbell C, Fan X, Dikiy S, Van Der Veeken J, Deroos P, et al. Metabolites produced by commensal bacteria promote peripheral regulatory T-cell generation. Nature. (2013) 504:451-5. doi: 10.1038/nature12726

30. Thorburn AN, McKenzie CI, Shen S, Stanley D, MacIa L, Mason LJ, et al. Evidence that asthma is a developmental origin disease influenced by maternal diet and bacterial metabolites. Nat Commun. (2015) 6:7320. doi: $10.1038 /$ ncomms 8320

31. Vieira R, de S, Castoldi A, Basso PJ, Hiyane MI, Câmara NOS, et al. Butyrate Attenuates Lung Inflammation by Negatively Modulating Th9 Cells. Front Immunol. (2019) 10:67. doi: 10.3389/fimmu.2019.00067

32. Kaplan MH, Hufford MM, Olson MR. The development and in vivo function of T helper 9 cells. Nat Rev Immunol. (2015) 15:295-307. doi: 10.1038/nri3824

33. Pizzolla A, Oh DY, Luong S, Prickett SR, Henstridge DC, Febbraio MA, et al. High fat diet inhibits dendritic cell and $\mathrm{T}$ cell response to allergens but does not impair inhalational respiratory tolerance. PLoS ONE. (2016) 11:e0160407. doi: 10.1371/journal.pone.0160407

34. Wheeler ML, Limon JJ, Bar AS, Leal CA, Gargus M, Tang J, et al. Immunological Consequences of Intestinal Fungal Dysbiosis. Cell Host Microbe. (2016) 19:865-73. doi: 10.1016/j.chom.2016. 05.003

35. Skalski JH, Limon JJ, Sharma P, Gargus MD, Nguyen C, Tang J, et al. Expansion of commensal fungus Wallemia mellicola in the gastrointestinal mycobiota enhances the severity of allergic airway disease in mice. PLoS Pathog. (2018) 14:e1007260. doi: 10.1371/journal.ppat.1007260

36. Shao TY, Ang WXG, Jiang TT, Huang FS, Andersen H, Kinder JM, et al. Commensal candida albicans positively calibrates systemic Th17 immunological responses. Cell Host Microbe. (2019) 25:404-17.e6. doi: 10.1016/j.chom.2019.02.004

37. Li X, Leonardi I, Semon A, Doron I, Gao IH, Putzel GG, et al. Response to fungal dysbiosis by gut-resident CX3CR1 + mononuclear phagocytes aggravates allergic airway disease. Cell Host Microbe. (2018) 24:847-56.e4. doi: 10.1016/j.chom.2018.11.003

38. Ege MJ, Mayer M, Normand AC, Genuneit J, Cookson WOCM, Braun-Fahrländer C, et al. Exposure to environmental microorganisms and childhood asthma. $N$ Engl J Med. (2011) 364:701-9. doi: 10.1056/NEJMoa1007302

39. Alfvén T, Braun-Fahrländer C, Brunekreef B, Von Mutius E, Riedler J, Scheynius A, et al. Allergic diseases and atopic sensitization in children related to farming and anthroposophic lifestyle - The PARSIFAL study. Allergy Eur J Allergy Clin Immunol. (2006) 61:414-21 doi: 10.1111/j.1398-9995.2005.00939.x

40. Riedler J, Braun-Fahrländer C, Eder W, Schreuer M, Waser M, Maisch $\mathrm{S}$, et al. Exposure to farming in early life and development of asthma and allergy: a cross-sectional survey. Lancet. (2011) 358:1129-33. doi: 10.1016/S0140-6736(01)06252-3

41. Loss G, Apprich S, Waser M, Kneifel W, Genuneit J, Büchele G, et al. The protective effect of farm milk consumption on childhood asthma and atopy: the GABRIELA study. J Allergy Clin Immunol. (2011) 128:7663.e4doi: 10.1016/j.jaci.2011.07.048

42. Fujimura KE, Sitarik AR, Havstad S, Lin DL, Levan S, Fadrosh D, et al. Neonatal gut microbiota associates with childhood multisensitized atopy and T cell differentiation. Nat Med. (2016) 22:1187-91. doi: 10.1038/nm. 4176

43. Lluis A, Depner M, Gaugler B, Saas P, Casaca VI, Raedler D, et al. Increased regulatory T-cell numbers are associated with farm milk exposure and lower atopic sensitization and asthma in childhood. J Allergy Clin Immunol. (2014) 133:551-9.E10. doi: 10.1016/j.jaci.2013.06.034

44. Schröder PC, Illi S, Casaca VI, Lluis A, Böck A, Roduit C, et al. A switch in regulatory $\mathrm{T}$ cells through farm exposure during immune maturation in childhood. Allergy Eur J Allergy Clin Immunol. (2017) 72:604-15. doi: 10.1111/all.13069

45. Korpela K, Salonen A, Virta LJ, Kekkonen RA, Forslund K, Bork P, et al. Intestinal microbiome is related to lifetime antibiotic use in Finnish pre-school children. Nat Commun. (2016) 7:10410. doi: 10.1038/ncomms 10410

46. Stinson LF, Payne MS, Keelan JA. A critical review of the bacterial baptism hypothesis and the impact of cesarean delivery on the infant microbiome. Front Med. (2018) 5:518. doi: 10.3389/fmed.2018. 00135

47. Almqvist C, Cnattingius S, Lichtenstein P, Lundholm C. The impact of birth mode of delivery on childhood asthma and allergic diseases-a sibling study. Clin Exp Allergy. (2012) 42:1369-76. doi: 10.1111/j.1365-2222.2012. 04021.x

48. Durack J, Kimes NE, Lin DL, Rauch M, McKean M, McCauley K, et al. Delayed gut microbiota development in high-risk for asthma infants is temporarily modifiable by Lactobacillus supplementation. Nat Commun. (2018) 9:707. doi: 10.1038/s41467-018-03157-4

49. Cabana MD, McKean M, Caughey AB, Fong L, Lynch S, Wong A, et al. Early probiotic supplementation for eczema and asthma prevention: a randomized controlled trial. Pediatrics. (2017) 140:e20163000. doi: $10.1542 /$ peds.2016-3000 
50. Clark RA. Resident memory $\mathrm{T}$ cells in human health and disease. Sci Transl Med. (2015) 7:269rv1 doi: 10.1126/scitranslmed. 3010641

51. Mackenzie KJ, Nowakowska DJ, Leech MD, McFarlane AJ, Wilson C, Fitch $\mathrm{PM}$, et al. Effector and central memory T helper 2 cells respond differently to peptide immunotherapy. Proc Natl Acad Sci USA. (2014) 111:e784-93. doi: 10.1073/pnas.1316178111

52. Lawrence MG, Steinke JW, Borish L. Basic science for the clinician: mechanisms of sublingual and subcutaneous immunotherapy. Ann Allergy Asthma Immunol. (2016) 117:138-42. doi: 10.1016/j.anai.2016. 06.027
Conflict of Interest: The authors declare that the research was conducted in the absence of any commercial or financial relationships that could be construed as a potential conflict of interest.

Copyright $(2) 2020$ Di Gangi, Di Cicco, Comberiati and Peroni. This is an open-access article distributed under the terms of the Creative Commons Attribution License (CC $B Y)$. The use, distribution or reproduction in other forums is permitted, provided the original author(s) and the copyright owner(s) are credited and that the original publication in this journal is cited, in accordance with accepted academic practice. No use, distribution or reproduction is permitted which does not comply with these terms. 